\title{
Yaşlılarda Fiziksel İnaktivitenin Yaşam Kalitesi Üzerine Etkileri
}

\section{Physical Inactivity Effects on Quality of Life in the Elderly}

\author{
Tahir Belice $^{1}$, Selman Bölükbaşı ${ }^{2 *}$, Aliye Mandıracıŏlu ${ }^{3}$ \\ ${ }^{1}$ İzmir Bozyaka Eğitim ve Araştırma Hastanesi Dahiliye Anabilim Dalı, İzmir, Türkiye \\ ${ }^{2}$ Manisa Aile, Çalışma ve Sosyal Hizmetler İl Müdürlüğü Yaşlı Hizmetleri Birimi, Manisa, Türkiye \\ ${ }^{3}$ Ege Üniversitesi Halk Sağlığı Anabilim Dalı, İzmir, Türkiye \\ e-mail: drtahirelf@hotmail.com, selmanbolukbasi@yandex.com, aliye2kuru@yahoo.com \\ ORCID: 0000-0001-7957-3423 \\ ORCID: 0000-0003-3771-4827 \\ ORCID: 0000-0002-0873-4805 \\ *Sorumlu yazar/ Corresponding Author: Selman Bölükbaşı \\ Gönderim Tarihi / Received: 26.06.2020 \\ Kabul Tarihi / Accepted: 23.11.2020 \\ DOI: $10.34087 /$ cbusbed. 758231
}

\begin{abstract}
Giriş ve Amaç: Sedanter yaşam tarzının yaşlıların sağlı̆̆ını olumsuz etkilediği bilinmektedir. Bu çalışmanın amacı huzurevinde yaşayan yaşıı bireylerde sedanter yaşam tarzı ile yaşam kalitesi arasındaki ilişkiyi araştırmaktır.

Gereç ve Yöntemler: Manisa'daki Huzurevleri bu kesitsel çalışmaya dahil edilmiş olup çalışmaya dahil edilen bireylerin toplam sayısı 181'dir ve veriler yaşlılarla yüz yüze görüşülerek toplanmıştır. Veri toplama formu 3 bölümden oluşmaktadır: Fiziksel Etkinliklerin Hızlı Değerlendirilme Ölçeği (RAPA 1 ve 2), Dünya Sağlık Örgütü Yaşam Kalitesi Ölçeği Yaşlı sürümü (WHOQOL-old) ve demografik özellikler. Yaşam kalitesi ile fiziksel aktivite ve yaşlıların diğer özellikleri arasındaki ilişkiyi değerlendirmek için bağımsız gruplarda t testi ve tek yönlü varyans analizi (ANOVA) kullanılmıştır. Değişkenler arasındaki anlamlı fark 0,05 düzeyinde yorumlanmıştır.

Bulgular: Cinsiyet dağılımı aşağıdaki gibidir: Kadın: \%31,5; erkek: \%68,5. Kronik hastalıklar \%56,4 oranında iken, katılımcıların \% 73,5'in sedanter bir yaşam tarzı olduğu bulunmuştur. Sedanter yaşam tarzı ile yaşam kalitesi ölçeğinin toplam puanları (t: -7,124, p: 0,003), özerklik (t: $-1,270$, p: 0,005), faaliyetler (t: $-0,965, \mathrm{p}: 0,043)$ ve duyusal yetenek $(\mathrm{t}:-2,172$, p: 0,001) arasında negatif bir korelasyon bulunmuştur.

Sonuç: Yaşlıların yaşam kalitesini etkileyen birçok faktör olmasına rağmen, yaşlılarda sedanter yaşam tarzı ve WHOQOL-old ölçeğinin toplam puanları arasında anlamlı bir ilişki vardır. Huzurevlerinde yaşlıların daha aktif olmalarını sağlayacak hizmetler yer verilmelidir.
\end{abstract}

Anahtar kelimeler: Egzersiz, Huzurevleri, Sedanter davranış, Yaşam kalitesi, Yaşlı.

\begin{abstract}
Objective: It is known that sedentary lifestyle affects older adults' health negatively. This study aim was to investigate the relationship between sedentary lifestyle and quality of life in elderly individuals living in a nursing home.

Material and Methods: Nursing Homes in Manisa were included in this cross-sectional study. The total number of individuals included in the study was 181 and the data were collected via face-to-face interview with the elderly. The data collection form comprised 3 parts as follows: The Rapid Assessment of Physical Activity Scale (RAPA 1 and 2), World Health Organization Quality of Life Instrument Older Adults Module (WHOQOL-old) and demographic characteristics. Independent groups t-test and one-way analysis of variance (ANOVA) were used to evaluate the relationship between quality of life and physical activity and other characteristics of the elderly. The significant difference between the variables was interpreted at the level of 0.05 .

Results: Gender distributions were as follows: female: $31,5 \%$, male: $68,5 \%$. While those with chronic diseases were $56.4 \%$, the participants were found to have a sedentary lifestyle of $73,5 \%$. There was found a negative correlation between sedentary lifestyle and total scores of quality of life scale (t: -7,124, p: 0,003), autonomy $(\mathrm{t}:-1,270, \mathrm{p}: 0,005)$, activities (t: $-0,965, \mathrm{p}: 0,043)$, sensory ability (t: $-2,172, \mathrm{p}: 0,001)$ domains.
\end{abstract}


Conclusion: Although there are many factors that affect the elderly's quality of life, there is a relationship between sedentary lifestyle and total scores of WHOQOL-old scale in the elderly. In the nursing homes, services should be provided to enable the elderly to be more active.

Keywords: Aged, Exercise, Nursing homes, Quality of Life, Sedentary behavior.

\section{Giriş}

Yaşam süresinin uzaması ve yaşlıların daha da sağlıklı olmaları demografi yapımızda bir değişimi de beraberinde getirmektedir [1]. Dünya yaşlı nüfusu 2050 yılı itibari ile yaklaşık olarak toplam nüfusun \%17'sini kapsaması beklenmektedir [2]. Yaşlıların günlük yaşamda oturarak geçirdikleri sürenin artması beraberinde abdominal yağlanma, lipid profilinin bozulması, kalp hastalıklarında artış, glisemik regülasyonun bozulması ve sağlı algısında kötüleşmeyi ortaya çıkarmaktadır $[3,4]$. Fiziksel aktivitenin sağlıklı yaşlanmanın bir parçası olduğu ve kronik hastalıklar ile fiziksel inaktivite arasında pozitif bir korelasyonun varlığı birçok çalışma ile gösterilmiştir [5]. Yaşlanmanın kardiyorespiratuvar ve kas-iskelet sistemindeki zayıflama ile ilişkili olduğu bilinmekle beraber, bu değişikliklerin bir kısmı da sedanter yaşam tarzına bağlanabilmektedir [6]. Bir sistematik derlemede dünyadan 53 makale değerlendirilmiş ve 60 yaş üzeri kişilerin kendi bildirimlerine göre değerlendirildiğinde fiziksel aktivite sıklığının \%6,2- \%82,6 arasında değiştiği bildirilmektedir [7]. Türkiye kronik hastalıklar ve risk faktörleri sıklığı çalışmasının sonuçlarına göre, $65-74$ yaş grubunun \%15,1'inin yeterli \%24,7'ünün orta ve $\%$ 60,2'nin yetersiz fiziksel aktivitesi olduğu anlaşılmıştır. $\mathrm{Bu}$ çalışmada 75 yaş üzerinde sedanter durumun daha da $\operatorname{artt1ğ} 1$ sadece \%10,8'inin yeterli aktivitede bulunduğu belirlenmiştir [8].

Dünya Sağlı Örgütü yaşam kalitesini "kişilerin içerisinde bulundukları kültür ve değerler sisteminde; beklentileri, standartları, amaçları ve kaygıları açısından, yaşamdaki konumları algılaması" olarak tanımlamakta olup sağlıklı ve aktif yaşamak vurgusunu yapmaktadır [9]. Yaşam kalitesi fiziksel, fonksiyonel, duygusal ve sosyal faktörlerin bir kombinasyonundan sonuçlanan bir iyilik hali olarak da tanımlanabilir [10]. Düşük ekonomik, kültürel, eğitim ve sağlık koşulları ile yetersiz sosyal etkileşim düşük yaşam kalitesi düzeyi ile ilişkili bulunmuştur [11,12]. Pek çok çalışmada fiziksel aktivitenin yaşam kalitesi üzerine etkisi olduğu bildirilmektedir. Çalışmalarda farklı yaşam kalitesi ölçekleri ve fiziksel aktivite değerlendirme yöntemleri kullanılmış olsa da yapılan fiziksel aktivitenin yaşam kalitesi üzerine etkisinin olduğu gösterilmiştir [13-14].

Huzurevlerinde kalan yaşlılara yeme, içme, barınma gibi gündelik gereksinimlerin karşılanmasının yanında, tıbbi bakım ve tedavilerinin yapılması, sosyal sorunlarının çözümünde destek olunması zamanlarının değerlendirilerek, sosyal ilişkilerinin geliştirilmesi, aktivitelerinin devamının sağlanmasını amaçlayan hizmetler sunulmaktadır. Huzurevlerinde yaşlı erişkinlere sunulan hizmetlerin amacı, yaşam kalitelerini koruyarak aktif bir yaşam sürmelerini sağlamaktır [15]. Sedanter yaşam biçimi ülkemizde her yaşta yaygındır ve bu durum ileri yaşta kazanılmış bir alışkanlık olarak devam etmektedir. Üstelik kronik hastalıklar ve bazı sağlık sorunlarının artışı, yaşlılarda fiziksel aktivite isteğini daha da azaltabilmektedir. Huzurevlerinde yaşayan yaşlıların durumlarının değerlendirilerek yapılacak hizmetlerin yönlendirilmesi önemlidir. Çalışmanın amacı, Manisa'da huzurevlerinde yaşamlarını sürdüren 60 yaş üzeri kişilerin fiziksel aktivite ve yaşam kalitesi durumlarının belirlenmesidir.

\section{Materyal ve Metot}

Bu kesitsel çalışma Manisa'daki 4 resmi 1 özel olmak üzere 5 huzurevini kapsamaktadır. Ege Üniversitesi Rektörlüğü Tıp Fakültesi Dekanlığı Tıbbi Araştırmalar Etik Kurulu 30.05.2019 tarihli ve 19-5.2T/32 sayılı Onay Kararı ve Manisa Valilik Makamının 13.06.2019 tarihli ve 1469725 sayılı Onayı alınarak çalışmaya başlanmış, bu çalışmaya bilişsel durumu iletişim kurmaya uygun ve fiziksel aktivite yapmaya bir engeli olmayan 60 yaş ve üzeri kişiler dâhil edilmiştir. Bu kriterlere uygun toplam 181 yaşlıdan veriler yüz yüze görüşülerek toplanmıştır. Veri toplama formu 3 bölümden oluşmaktadır: Fiziksel Aktivite Hızlı Değerlendirme Ölçeği (RAPA 1 ve 2), Dünya Sağlık Örgütü Yaşam Kalitesi Ölçeği Yaşlı sürümü (WHOQOL-old) ve demografik bilgilerin elde edilmesine yönelik bir anket formu. Fiziksel Aktivite Hızlı Değerlendirme Ölçeği Topolski vd. tarafından geliştirilmiştir [16]. Türkçe geçerlilik ve güvenirlilik çalışması Çekok ve vd. tarafından gerçekleştirilmiştir [17]. RAPA 2 bölümden oluşmaktadır. Birinci bölümde sedanter veya aktif olma durumları, 2. bölümde ise esneklik değerlendirilmektedir. WHOQOL-old ölçeği Eser vd. tarafından Türkçe'ye uyarlanmıştır. WHOQOLold modülü, altı boyuttan oluşmakta ve beşli Likert ile yanıtlanabilen 24 sorudan oluşmaktadır. Özerklik, geçmiş-bugün-gelecek faaliyetleri, sosyal katılım, ölüm ve ölmek, yakınlık ve duyusal fonksiyonlar alt boyutlarını içermektedir. Alt ölçek puanları, 4-20 arasındadır ve "toplam puan" da hesaplanabilir. Puan arttıkça yaşam kalitesi de iyileşmektedir [18]

\subsection{Istatistiksel Analiz}

Yaşam kalitesi ile fiziksel aktivite ve yaşlıların diğer özellikleri arasındaki ilişkiyi değerlendirmek için bağımsız gruplarda $t$ testi ve tek yönlü varyans analizi (ANOVA) kullanılmıştır. Değişkenler arasındaki anlamlı fark 0,05 düzeyinde yorumlanmıştır. Katılımcılar, gönüllük esasına göre bilgilendirilmiş onam formlarını doldurulup imzalandıktan sonra çalışmaya alınmışlardır.

\section{Bulgular ve Tartışma \\ 3.1 Bulgular}

Toplam katılımcı sayısı toplam 5 huzurevinden 181 kişi olup, cinsiyet dağılımları kadın: \%31,5 (n: 57), erkek: \%68,5 (n: 124) olarak saptanmıştır. Kronik hastalığı olanların oranı \%56,4 (n: 102) iken, katılımcıların \%73,5 (n: 133) sedanter yaşadığı 
Tablo 1. Araştırmada Yer Alan 60 Yaş Üzeri Kişilerin Özellikleri

\begin{tabular}{|c|c|c|}
\hline & Sayı & $\%$ \\
\hline \multicolumn{3}{|l|}{ Cinsiyet } \\
\hline Erkek & 124 & 68,5 \\
\hline Kadın & 57 & 31,5 \\
\hline \multicolumn{3}{|l|}{ Eğitim Durumu } \\
\hline Okur-yazar değil & 24 & 13,3 \\
\hline Okur-yazar & 29 & 16,0 \\
\hline İlkokul & 80 & 44,2 \\
\hline Ortaokul & 22 & 12,2 \\
\hline Lise & 15 & 8,3 \\
\hline Üniversite ve Üstü & 11 & 6,1 \\
\hline \multicolumn{3}{|l|}{ Kronik Hastalık } \\
\hline Var & 102 & 56,4 \\
\hline Yok & 79 & 43,6 \\
\hline \multicolumn{3}{|l|}{ VKİ* sinıflama } \\
\hline Zayıf & 5 & 2,8 \\
\hline Normal & 83 & 45,9 \\
\hline Kilolu & 86 & 47,5 \\
\hline \multicolumn{3}{|l|}{ Sedanterlik } \\
\hline Sedanter & 133 & 73,5 \\
\hline Sedanter değil & 48 & 26,5 \\
\hline \multicolumn{3}{|l|}{ Esneklik } \\
\hline Esnek değil & 162 & 89,5 \\
\hline Esnek & 19 & 10,5 \\
\hline
\end{tabular}

bulunmuştur. Tablo 1'de katılımcıların özellikleri izlenmektedir.

Tablo 2'de görüldüğü gibi yaşlıların toplam yaşam kalitesi ölçek puanının sedanter yaşam tarzı tanımlanan kişilerde daha düşük olduğu saptanmıştır $(p<0,05)$. Yaşam kalitesi ölçeğinin alt ölçeklerinden özerklik, geçmiş-bugün-gelecek faaliyetler ve duyusal fonksiyon alan puanları ve sedanter yaşam tarzı arasında ilişki belirlenmiştir ( $\mathrm{p}<0,05)$. Sosyal katılım, ölüm ve yakınlık alt boyutlarında herhangi istatistiksel bir anlamlılık saptanmamıştır $\quad(p>0,05)$ RAPA-2 ölçeği ile değerlendirilen esneklik ve yaşam kalitesi ile özerklik alt boyutu hariç herhangi bir anlamlı ilişki saptanmamıştır. Kronik hastalık durumu, cinsiyet ve vücut kitle indeksinin yaşam kalitesi ölçeği toplam skorları ve her bir alt boyutu arasında anlamlı bir ilişki saptanmamıştır $(0>0,05)$. Eğitim durumu ise toplam yaşam kalitesi ölçeği skorları, özerklik ve ölüm alt boyutu ile karşılaştırıldığında anlamlı bir ilişki saptanmıştır $(\mathrm{p}<0,05)$.

\section{Tartıșma}

Yaşlılarda fiziksel fonksiyonların korunması ile yaşamdan tatmin olma ve güvende hissetme durumunun olumlu olarak etkilendiği bilinmektedir [19]. Çalışmamızda katılımcıların \%26,5'inin aktif yaşam tarzına sahip olduğu saptanmıştır. Aynı RAPA ölçeği kullanılarak fiziksel aktivitenin değerlendirildiği çalışmalarda İzmir'de \%25,5, ABD'de \%24, İran'da $\% 13,7$ olarak bildirilmiştir [17, 20, 21].

Manisa huzurevlerinde yapılan bu çalıșmada yaşlıların yaşam kalitesi ile fiziksel aktif olma durumları arasında ilişki olduğu belirlenmiştir. Farklı ülkelerde farklı yaşam

Tablo 2. RAPA Ölçeğine Göre Sedanter Yaşam İle Yaşam Kalitesi Karşıısaşırması

\begin{tabular}{|c|c|c|c|c|c|}
\hline \multicolumn{2}{|c|}{ Yaşam kalitesi Ölçeği } & $\mathrm{N}$ & Ortalama & SS & $\mathrm{t}, \mathrm{p}$ \\
\hline \multirow[t]{2}{*}{ Toplam ölçek } & Sedanter & 131 & 82,3435 & 14,76679 & $\begin{array}{l}-7,124 \\
0,003\end{array}$ \\
\hline & Aktif & 47 & 89,4681 & 10,23390 & \\
\hline \multirow[t]{2}{*}{ Özerklik } & Sedanter & 133 & 13,7293 & 2,70277 & $\begin{array}{l}-1,270 \\
0,005\end{array}$ \\
\hline & Aktif & 48 & 15,0000 & 2,39681 & \\
\hline \multirow[t]{2}{*}{ Duyarlılık } & Sedanter & 132 & 14,1818 & 4,18069 & $\begin{array}{l}-2,172 \\
0,001\end{array}$ \\
\hline & Aktif & 48 & 16,3542 & 3,30370 & \\
\hline \multirow[t]{2}{*}{ Faaliyetler } & Sedanter & 133 & 13,4511 & 2,88535 & $\begin{array}{l}-0,965 \\
0,043\end{array}$ \\
\hline & Aktif & 48 & 14,4167 & 2,61610 & \\
\hline \multirow[t]{2}{*}{ Sosyal katılım } & Sedanter & 133 & 12,7068 & 4,72707 & \\
\hline & Aktif & 48 & 13,7500 & 2,47970 & $\mathrm{p}>0,05$ \\
\hline \multirow[t]{2}{*}{ Ölüm } & Sedanter & 132 & 13,9773 & 4,26859 & \\
\hline & Aktif & 47 & 15,1702 & 3,54670 & $p>0,05$ \\
\hline \multirow[t]{2}{*}{ Yakınlık } & Sedanter & 133 & 14,3383 & 3,49651 & \\
\hline & Aktif & 48 & 14,7708 & 3,19734 & $p>0,05$ \\
\hline
\end{tabular}


kalitesi ölçekleri ile yürütülen çalışmalarda da aynı sonuçlar elde edilmiştir. Hem evlerinde yaşayan ve hem de kurumda yaşayan yaşlilardan fiziksel olarak aktif olanlar yaşam kalitesi ölçeklerinden yüksek puan almışlardır [13, 22, 23]. WHOQOL-old ölçeği kullanılarak yapılan bir çalışmada yeterli ve düzenli aktif olan kent yaşlılarında yaşam kalitesi toplam puanı $63,5 \pm 13,1$; fiziksel alanda $60,1 \pm 14,4$; psikolojik alanda $71,5 \pm 11,8$; sosyal ilişkiler alt boyutta $70,8 \pm 12,6$; çevre alt boyutta 57,8 $\pm 17,5$ olarak hesaplanmıştır [24]. Çalışmada sosyal katılım, ölüm ve yakınlık alt ölçek puanları ile fiziksel aktivitenin ilişkili olması, yaşlıların huzurevlerinde kalan diğer bireyler ile sürekli bir etkileşim halinde olması neticesinde ortaya çıktığ söylenebilir. Yalnızlık nedeniyle yaşlıların birçoğu sağlık yönünden olumsuz olarak etkilenmektedir ve giderek yaşlanan bir toplumda yalnızlık artan bir sorun haline gelmektedir. İleri yaş döneminde yaşam kalitesi sağlıklı olabilmek kadar önemlidir. Huzurevleri yaşlıların kolaylıkla sosyalleşebileceği ortamlardır. Pek çok aktivite konusunda bu yaşlıların motivasyonları daha kolay sağlanabilmekte, topluca bir amaca yönelik harekete geçilebilmekte, bir kişinin davranış değişikliği için gereken sosyal ve çevresel destek çok kolay elde edilebilmektedir [25].

\subsection{Limitasyonlar}

Çalışma Manisa huzurevlerinde kalan alan 60 yaş ve üstü bireylerde yürütüldüğü için genellenebilir değildir. Kesitsel bir araştırma olduğu için neden-sonuç ilişkisini belirleme gücü yetersizdir. Diğer taraftan çalışmada yer alan grup kurumda yaşayan yaşlilara uygun bir profile sahip oldukları için elde edilen sonuçlar çok fikir vericidir.

\section{Sonuç}

Yaşlıların yaşam kalitesini etkileyen birçok faktör olmasına rağmen, yaşlilarda sedanter yaşam tarzı ve WHOQOL-old ölçeğinin toplam puanları arasında anlamlı bir ilişki vardır. Huzurevi görevlileri yaşlıları fiziksel aktivite konusunda yaşlıları cesaretlendirmeli, destekleyici yöntemler ile olanak sağlamalıdır. Huzurevlerinde yaşlıların daha aktif olmalarını sağlayacak organize hizmetler yer verilmelidir.

\section{Referanslar}

1. United Nations, World Population Ageing: 1950-2050 Department of Economic and Social Affairs PD; United Nations Publications: New York, 2001.

2. US Census Bureau, International Population Reports WP/02, Global Population Profile: 2002; U.S. Government Printing Office: Washington DC, 2004

3. Gardiner, P.A, Healy, G.N, Eakin, E.G, Clark, B.K, Dunstan, D.W, Shaw, J.E, Zimmet, P.Z, Owen, N, Associations between television viewing time and overall sitting time with the metabolic syndrome in older men and women: the Australian Diabetes, Obesity and Lifestyle study, Journal of the American Geriatrics Society, 2011, 59(5), 788 96.

4. Copeland, J.L, Clarke, J, Dogra, S, Objectively measured and selfreported sedentary time in older Canadians, Preventive Medicine Reports, 2015, 2, 90-5.

5. Hallal, P.C, Andersen, L.B, Bull, F.C, Guthold, R, Haskell, W, Ekelund, U, Global physical activity levels: surveillance progress, pitfalls, and prospects, Lancet, 2012, 380(9838), 247-57.
6. Trappe, S, Hayes, E, Galpin, A, Kaminsky, L, Jemiolo, B, Fink, W, et al., New records in aerobic power among octogenarian lifelong endurance athletes, Journal of Applied Physiology (Bethesda, Md.:1985), 2013, 114(1), 3-10.

7. Sun, F, Norman, I.J, While, A.E, Physical activity in older people: a systematic review, BMC Public Health, 2013, 13, 449.

8. Üner, S, Balcılar, M, Ergüder, T, WHO International. https://www.who.int/ncds/surveillance/steps/Factsheet-STEPSTurkey-TUR-08.10.2018.pdf., 2018 (accessed 10.08.2018).

9. World Health Organization (WHO), Ageing and Health Programme, Growing Older Staying Well; WHO/HPR/AHE/98.2: Geneva, Switzerland, 1998.

10. Haan, R.J, Measuring Quality of Life After Stroke Using the SF-36, Stroke, 2002, 33(5), 1176-1177.

11. Mellor, D, Russo, S, McCabe, M.P, Davison, T.E, George, K, Depression training program for caregivers of elderly care recipients: implementation and qualitative evaluation, Journal of Gerontological Nursing, 2008, 34(9), 8-17.

12. Donmez, L, Gokkoca, Z, Dedeoglu, N, Disability and its effects on quality of life among older people living in Antalya city center. Archives of Gerontology and Geriatrics, 2005, 40(2), 213-223. doi: 10.1016/j.archger.2004.08.006.

13. Acree, L.S, Longfors, J, Fjeldstad, A.S, Fjeldstad, C, Schank, B, Nickel, K.J, Montgomery, P.S, Gardner, A.W, Physical activity is related to quality of life in older adults, Health Qual Life Outcomes, 2006, 4:37.

14. Rejeski, W.J, Mihalko, S.L, Physical activity and quality of life in older adults, The journals of Gerontology, 2001, 56 Spec No 2, 23 35 .

15. Fadıloğlu, Ç, İlkbay, Y, Yıldırım, Y, Huzurevinde kalan yaşlılarda uyku kalitesi, Türk Geriatri Dergisi, 2006, 9(3), 165-169.

16. Topolski, T.D, LoGerfo, J, Patrick, D.L, Williams, B, Walwick, J, Patrick, M.B, The Rapid Assessment of Physical Activity (RAPA)among older adults, Preventing Chronic Disease, 2006, 3(4), A118.

17. Cekok, F.K, Kahraman, T, Kalkıșım, M, Genç, A, Keskinoğlu, P, Cross-cultural adaptation and psychometric study of the Turkish version of the Rapid Assessment of Physical activity, Geriatrics \& Gerontology International, 2017, 17(11), 1837-1842.

18. Eser, E, Eser, S, Özyurt, B.C, Fidaner, C, Perception of quality of life by a sample of Turkish older adults: WHOQOL-OLD project Turkish focus group results, Turkish Journal of Geriatrics, 2005, 8(4), 169 183.

19. Rejeski, W.J, King, A.C, Katula, J.A, Kritchevsky, S, Miller, M.E, Walkup, M.P, Glynn, N.W, Pahor, M, LIFE Investigators, Physical activity in prefrail older adults: confidence and satisfaction related to physical function, The Journals of Gerontology, 2008, 63(1), P19-26.

20. Mayer, C.J, Steinman, L, Williams, B, Topolski, T.D, LoGerfo, J, Developing a Telephone Assessment of Physical Activity (TAPA) questionnaire for older adults, Preventing Chronic Disease, 2008, 5(1), A24.

21. Eshaghi, S.R, Shahsanai, A, Ardakani, M.M, Assessment of the Physical Activity of Elderly Population of Isfahan, Iran, Journal of Isfahan Medical School, 2011, 29(147), 939-946.

22. McAuley, E, Konopack, J.F, Motl, R.W, Morris, K.S, Doerksen, S.E, Rosengren, K.R, Physical activity and quality of life in older adults: influence of health status and self-efficacy, Annals of Behavioral Medicine: A Publication of The Society of Behavioral Medicine, 2006, 31(1), 99-103. doi: 10.1207/s15324796abm3101_14.

23. Pernambuco, C.S, Rodrigues, B.M, Bezerra, J.C.P, Carrielo, A, Fernandes, A.D.O, Vale, R.G.S, Dantas, E.H.M, Quality of life, elderly and physical activity, Health, 2012,4,88-93.

24. Barbosa, A.P, Teixeira, T.G, Orlandi, B, Oliveira, N.T.B, Concone, M.H.V.B, Level of physical activity and quality of life: a comparative study among the elderly of rural and urban areas, Revista Brasileira de Geriatria e Gerontologia, 18(4), 743-754.

25. Koltyn, K.F, The association between physical activity and quality of life in older women, Womens Health Issues, 2001, 11(6), 471-480.

http://edergi.cbu.edu.tr/ojs/index.php/cbusbed isimli yazarın CBU-SBED başlıklı eseri bu Creative Commons 
Alıntı-Gayriticari4.0 Uluslararası Lisansı ile lisanslanmıştır

\section{(c) $(1)(9)$}

